\title{
Gunshot wounds: the new public health issue
}

A new law that would make it mandatory for doctors in Ontario to report gunshot wounds to police is stirring up debate within Canada's emergency medicine community.

If approved by the legislature this spring, the controversial law will become the first of its kind in the country.

Currently hospital staff are not legally required to inform police when they treat a patient who has been injured by a firearm. But physicians are obligated to respect the confidentiality requests of their patients despite any demands for information from police.

This has led to high-profile standoffs between police investigators and emergency doctors in some cities over the right to protect patient confidentiality.

This reality seems to have been reflected in the announcement of the draft legislation by the province's Minister of Community Safety in December. "If someone has been shot, there's an absolute commitment and obligation on our part to find out who shot them [and] to make sure that whoever did it is not out there potentially able to shoot someone else," said Monte Kwinter.

The announcement came on the heels of a position statement

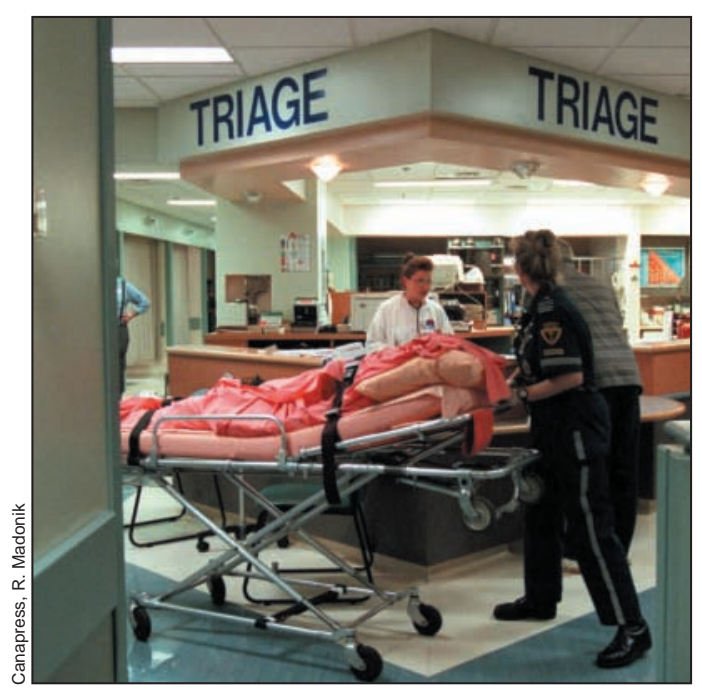

Ontario physicians may soon be required by law to report gunshot wounds. from the Ontario Medical Association in November, which recommended eliminating the current law.

Published by the OMA's Section on Emergency Medicine, the paper calls on legislators to pass a new law that would force doctors to report gunshot wounds. But Dr. Howard Ovens, who helped write the paper, said the basis of their position has little to do with appeasing law enforcement.

"We're approaching this issue from a public health perspective, rather than from a criminal justice point of view," said the director of the Schwartz/Reisman Emergency Centre at Toronto's Mount Sinai Hospital.

Ovens' research revealed that of the estimated 1000 firearmsrelated deaths in Canada every year, nearly $80 \%$ are suicides and only $15 \%$ are homiciderelated. About 4\% were deemed accidental.

For this reason, he says the OMA would like to see a law that requires doctors to report all gunshot wounds to police, in an effort to prevent, for example, future suicide attempts or potential accidents resulting from improper storage or handling of firearms.

"Obviously, as citizens we don't mind seeing criminals apprehended," Ovens said. "But we don't want to suggest that it's our job to help apprehend criminals. It's our job to help protect the public health."

But some emergency physicians are convinced that a mandatory reporting law would do more harm than good.

"Mandatory reporting would only serve to discourage [gunshot wound] patients from seeking medical care," said Dr. Simon Kingsley, who works in the emergency department at Toronto's St. Michael's Hospital, in a letter he wrote to the OMA.

If a patient with a gunshot wound actually did present to the ED, the law could induce him or her to give inaccurate information, he stated. "If patients were unwilling to co-operate in the first place, how would mandatory reporting increase their compliance to do so?"

The Canadian Association of Emergency Physicians, on the other hand, supports a more moderate approach. Although they have yet to issue a formal position on mandatory reporting, CAEP's president says the current law puts emergency physicians in an ethical quandary.

"The issue has always been Do you wear your hat as a physician or do you wear your hat as a member of the general public?," said François Bélanger, an emergency doctor at the Alberta Children's Hospital in Calgary. "It's a very difficult position. Anything that would clarify our role and help ease our members' ethical dilemmas would certainly be helpful."

Ideally, Bélanger would like to see a new law that would grant emergency physicians the discretion to determine which gunshot wounds need to be reported to police.

Meanwhile, the Ontario Association of Chiefs of Police is calling for an expanded law that would require doctors to report any injuries they think are a result of criminal activity, such as stabbings or beatings.

The suggestion has been rejected by both the OMA and CAEP.

Despite the debate, Ovens says a revised law is inevitable, especially when you consider that 48 US states already have laws requiring doctors to report gunshot wounds, and that Canadian doctors are already legally required to report suspected cases of child abuse, potential drunken drivers or patients with communicable diseases such as HIV and AIDS. - Bradford Mackay, Toronto 